\title{
In memoriam \\ María del Carmen Valverde Valdés
}

(1962-2020)

María del Carmen Valverde, la Dra. Valverde o la Queca, como cariñosamente le decía su familia, nos ha dejado, todavía difícil de creer. Para aquellos que tuvimos el gusto de conocerla, de tratarla y de tener su amistad ha sido un proceso largo y doloroso. No encuentro palabras para describir el gran vacío que deja en todos aquellos que la conocimos, en todos aquellos que fuimos receptores de su gran entrega como académica, o bien, para los que fue una maestra y, para muchos otros, amiga y colega. Fue en verdad dadivosa, un ser humano increíble. Los compañeros del Centro de Estudios Mayas, del Posgrado en Estudios Mesoamericanos y me atrevería a decir que muchos del Instituto de Investigaciones Filológicas, entidad a la que pertenecemos, hemos llorado su muerte.

Primero que nada, la Dra. Valverde fue una gran universitaria, consagró toda su vida a trabajar para la UNAM; sorprendía con la capacidad que tenía para para realizar múltiples tareas a la vez. Era una persona que sabía escuchar y apoyar a todos aquellos que se le acercaban, alumnos o compañeros, e invariablemente nos recibía con una sonrisa, una sonrisa franca y un corazón sincero. Cuando llegaba al Centro de Estudios Mayas escuchábamos su voz alegre que se desbordaba por el pasillo; saludaba y se iba a su cubículo; luego, se apresuraba a asistir a algún consejo, dictaminadora, conferencia, comisión o a impartir un curso, entre las múltiples actividades en las que participaba. Siempre estaba corriendo.

Conocí a Carmen en agosto de 1985, durante el Primer Coloquio Internacional de Mayistas, cuando ella tenía sólo 23 años; llegó a apoyarnos durante su desarrollo recomendada por la Dra. De la Garza, quien por cierto dice que era su mejor alumna. Desde ese momento hicimos una gran amistad y me percaté de su enorme capacidad de liderazgo y de la facilidad para solucionar cualquier obstáculo, siempre con entusiasmo; para ella no había imposibles, todo con trabajo se podía solucionar. Carmen había estudiado historia en la Facultad de Filosofía y Letras, y se titularía unos años después con la tesis El símbolo de la cruz entre los mayas, tema que retomaría en varios momentos para referirse a la geometría del universo maya. Desde ese momento mostraba su afición por la religión maya, en especial por la simbólica. Así, señalaba que la forma cruciforme tendría diferentes valencias y la consideraba como uno de los símbolos más ricos en la cultura maya, presente en la división cuatripartita del cosmos y los cuatro rumbos, el símbolo de la cuaternidad, del uno y por ende del axis mundi; era el maíz o el árbol de la vida, significados que, agregaba, se complementan y enriquecen; a su vez la relacionaba con las bandas cruzadas que simbolizan el cielo, los cuatro vientos, los rayos y la lluvia como energía renovadora de la tierra. Con la Conquista, al enriquecerse con la cruz cristiana, no se pierde sino se revitaliza en la cultura maya y es un elemento central en el culto de los mayas de hoy en día. Se convierte hasta en un símbolo de las rebeliones indígenas 
en contra del dominio español. Este último tema, de las rebeliones, sería retomado por la Dra. Valverde en sus últimas investigaciones.

Su tesis de doctorado fue El simbolismo del jaguar entre los mayas, de la cual se desprenderían múltiples publicaciones, entre ellas su libro Balam. El jaguar a través de los tiempos y los espacios del mundo maya; en esta obra profundiza sus conceptos sobre el símbolo que había iniciado años atrás y proporciona una explicación muy completa. La elección del jaguar no fue fortuita; era uno de los animales preferidos de su esposo Arcadio, y al serlo también de ella, publicaron un libro conjunto; es una figura que aparece en múltiples contextos del arte maya con diferentes significados y logra integrar y sistematizar en diversos apartados un sinnúmero de expresiones del felino en apariencia caóticas, y lo más relevante, consigue darle un sentido a cada expresión dentro de un todo coherente y estructurado. Asimismo, señalaba que es un animal vinculado con la oscuridad, con el inframundo y, por ende, con las cuevas, el poder y la guerra; una manifestación del sol nocturno y del dios GIII; es, por excelencia, el "señor de los animales", y por todo ello también un símbolo de vida que se asocia al poder regenerativo de la naturaleza y de la tierra fecundante; por sus atributos no deja de relacionarse con el maíz y el cacao, y en los mitos figura en el principio y el fin del mundo. Un dato que destacaba, que me parece relevante, es que el jaguar no es un dios, sino una epifanía de las energías sagradas y bien podría tratarse de que los dioses en un determinado momento se "felinizan" y adquieren las características del jaguar, o bien, otros animales toman algunas características de él. No dejaba de revisar etnografías para hablar de cambios y continuidades. Desde mi punto de vista, es su obra mejor lograda, porque no sólo nos deja esta publicación, sino muchas otras que amplían el tema: artículos, capítulos, o bien ponencias y conferencias donde profundiza y agrega diversas valencias del jaguar, además de acercarse a otras culturas mesoamericanas. De esta manera, con análisis exhaustivo y gran rigor científico, la autora le otorga al jaguar un sentido y una estructura significativa, por lo que podemos identificar a nuestra compañera como una Ixiq Bahlam.

Entre sus publicaciones derivadas están "Jaguar y Lirio acuático" o "Flora y fauna como insignia de poder entre los antiguos gobernantes mayas", donde muestra un nuevo interés: el simbolismo de la flora. Esto culminaría en el último proyecto en el que participó como corresponsable, titulado "Plantas sagradas de los mayas" y del que alcanzó a ver un libro, coordinado por la Dra. Mercedes de la Garza. En el proyecto colaboró con el catálogo de plantas para la página web, apoyando tanto en trabajo de campo como en lecturas referentes a los primeros años de la Conquista, y en la revisión de obras de botánica; también supervisó a los becarios del proyecto y organizó y dio seguimiento al seminario interdisciplinario.

A su vez, fue corresponsable de otros proyectos, entre los que destaca la "Guía de Arquitectura y Paisaje 'La Ruta Maya”, con la Junta de Andalucía, España, donde coordinó a decenas de investigadores de diversas disciplinas, logrando una publicación envidiable. Junto con la Universidad de Oriente, de Valladolid, Yucatán, coordinó el proyecto "Continuidad, cambios y rupturas en las tradiciones míticas mayas"; en éste abordó el último tema que alcanzó a desarrollar, posteriormente, como investigación principal: "Símbolos religiosos de las rebeliones indígenas en el área maya durante el siglo xIx", que tenía 
como propósito un análisis comparativo entre las rebeliones indígenas de la zona de los Altos de Chiapas y Guatemala, que tuvieron lugar durante el siglo xix. Allí continuó con su línea principal de investigación, ya que el estudio lo realizaba a partir de los símbolos religiosos de cada una de ellas. Si bien presentó algunos artículos y capítulos sobre este tema, el libro completo quedó inconcluso, hecho que según me consta, lamentó mucho, y por supuesto nosotros también. Sobre el mismo tema editó la obra titulada La resistencia en el mundo maya, en la que escribió un capítulo. Y todavía en 2019 fue co-coordinadora del libro Mesas, altares y tronos en la dinámica ritual de los pueblos mesoamericanos, coautora de la introducción y autora del capítulo "Gloria. Espacios rituales de las iglesias mayas de Quintana Roo”, del que no alcanzó a ver su publicación, aunque le dio seguimiento hasta que estuvo en prensa.

Eso de la coordinación de libros se le daba muy bien, como diría ella, y entre las múltiples publicaciones en las que participó también como co-coordinadora están Teoría e historia de las religiones (2 volúmenes), Piedra contra piedra. Estudios sobre la lítica maya y Sym-bolon. Ensayos sobre cultura, arte y religión, por citar los últimos.

Desde un año antes de que terminara su licenciatura, había ofrecido varios cursos en la secundaria y el bachillerato del Colegio Madrid, A.C., institución en la que había estudiado, y por su alto desempeño escolar la mandaron llamar como docente tanto en secundaria como en preparatoria. Sus vínculos con el colegio continuaron durante toda su vida, y ofreció allí alrededor de doce conferencias a lo largo de su trayectoria académica, una muestra recíproca de agradecimiento para la escuela que la había formado. Esto nos habla de su gran calidad humana.

A partir de la experiencia adquirida en el Colegio Madrid, como ella misma decía, continuó impartiendo diferentes cursos en la licenciatura en Etnohistoria de la Escuela Nacional de Antropología e Historia, y más adelante en la Escuela Nacional de Conservación, Restauración y Museografía "Manuel del Castillo Negrete", ambas del Instituto Nacional de Antropología e Historia. Esta joven maestra ingresó a la unAm en 1997, dictando por varios semestres la materia de Civilización Maya en la Facultad de Filosofía y Letras, pero sin abandonar del todo la Escuela de Restauración. Dejó la licenciatura para ingresar como docente del Posgrado en Estudios Mesoamericanos, con la asignatura Literatura Maya, en 2002, a la par que inició tres cursos diferentes en el Posgrado de MADEMS, dedicado a la preparación docente, que en algunos semestres coincidieron en temporalidad. Con posterioridad, en el posgrado impartió Cultura Maya y, en sus últimos años como docente, la Actividad Académica para la graduación, en la que apoyaba a los alumnos para finalizar su tesis; fue elegida para esta actividad por su forma de enseñanza didáctica y por tener una mente perfectamente estructurada que hacía que los alumnos reflexionaran y corrigieran sus investigaciones. Sin duda alguna, la maestra Valverde se distinguió en gran medida por la docencia, llegó a impartir cursos diferentes simultáneamente y, en total, podemos contabilizar cinco posgrados. Ello porque gozaba de una gran facilidad para expresar sus conocimientos en forma coherente y ordenada, que apoyaba con su extraordinaria memoria, y por el amor y entusiasmo que imprimía en cada materia que impartía. Para este momento su vida era un remolino, yendo y viniendo de curso en curso y recibiendo alumnos a los que dirigía la tesis. 
Estas tesis eran tanto de licenciatura como de los posgrados con los que colaboró, porque los alumnos que la conocían querían seguir trabajando con ella; así, se acercó a temas no sólo de la cultura maya, sino también a la tradición oral zoque o los espacios sagrados en Tenochtitlán, y hasta las estrategias de enseñanza para el aprendizaje de la historia, porque contaba con herramientas teóricas suficientes para comprender otros temas y darles una estructura coherente. El número de tesis que dirigió o en las que participó como sinodal es realmente asombroso; su capacidad para esquematizar una investigación era envidiable. Todo esto se acompañó de cursos de superación para ella misma, que le permitían permanecer actualizada, y dicha actualización era patente a su vez en todas las clases y seminarios que impartía. Me consta que era capaz de realizar lecturas con gran rapidez y comprensión, analizarlas y asimilarlas. Poseía una inteligencia privilegiada.

Pero no sólo impartió cursos escolarizados, sino que a lo largo de toda su vida académica participó en un sinnúmero de conferencias, diplomados, talleres, cursos de actualización, presentaciones de libros, talleres, con una gran variedad de temas y en múltiples instituciones académicas, llegando a tener más de 50 comunicaciones, en la Ciudad de México, en diversos estados de la República y en la Universidad de Salamanca. Porque la Dra. Valverde no sabía decir que no. Y como no sabía decir que no, dictaminó alrededor de veinticinco libros, además de más de 60 artículos, memorias, ponencias, proyectos para ingresar a los posgrados; siempre estaba ocupada, siempre cumplía y con una actitud positiva, nunca se quejó del trabajo.

En cuanto a los eventos académicos, participó con alrededor de 60 ponencias, nacionales e internacionales, talleres, cursos y conferencias en los que iba presentando sus avances de investigación. Pero ese entusiasmo fue más allá, porque también colaboró o coordinó múltiples eventos, alrededor de 70, como talleres, diplomados y ciclos de conferencias; dentro de ellos destacan los diplomados de "Teoría e Historia de las Religiones" y de "Análisis del mito", el "Curso-Taller de escritura jeroglífica maya", o bien el "Seminario Internacional de Epigrafía Maya”. Me atrevería a decir que sus apoyos más relevantes fueron durante los Congresos Internacionales de Mayistas, dos de ellos organizados mientras fue coordinadora del Centro de Estudios Mayas. En éstos se destacó por su capacidad emprendedora, su buena disposición a colaborar, su experiencia; y así, con su voz sonora presente en cada reunión de trabajo, impulsaba ideas que mejoraran cada congreso. Claramente recuerdo sus frases en los pasillos para animarnos a colaborar "rapidito y de buen modo", o bien "hay que hacerse útil". Hasta el último que se realizó en Chetumal, ya enferma, no se quería rendir y menos regresar a la Ciudad de México, porque le faltaba un día más que le tocaba supervisar. Esa era la Dra. Valverde.

Nunca dejó las actividades de difusión que le permiten a la unAm alcanzar un ámbito más amplio que el estrictamente académico, al que Carmen invariablemente contribuía. Llegó a presentar más de 30 libros en diferentes espacios, colaboró en guiones museográficos, fue invitada a diversos programas de radio y televisión, donde difundía sus sólidos conocimientos sobre los mayas, y concedió diversas entrevistas, porque exponer era lo suyo.

Dados sus conocimientos y capacidades, fue invitada a un sinnúmero de comités, ya sea académicos, editoriales, de evaluación, para premios o admisiones, para actualizar 
programas, consejos asesores, cuerpos colegiados, no sólo de la UNAM, sino de otras instituciones académicas, dejando siempre en alto al Instituto de Investigaciones Filológicas. Y para fortuna nuestra fue, como ya cité, coordinadora del Centro de Estudios Mayas del 2005 al 2010, distinguiéndose este periodo por el ambiente cálido entre todos nosotros y la alta productividad en la entidad. Otro cargo, al que me consta dedicó mucho tiempo y esfuerzo, fue como responsable de la Maestría en Docencia para la Educación Media Superior (MADEMS) en la línea disciplinaria de Historia, elegida por su larga y completa experiencia, tanto en la docencia como en la teoría de la historia, y al que le dedicó más de diez años; este posgrado se dedica a formar docentes expertos para la educación media superior y quién mejor que una investigadora con la trayectoria de la Dra. Valverde para ocupar este cargo; con posterioridad fue representante de la dirección ante al Comité Académico de MADEMS en el área de Historia. Al terminar este cargo, el rector la distinguió como coordinadora del Programa de Maestría y Doctorado en Estudios Mesoamericanos, cinco años en los que alcanzó en el Programa Nacional de Posgrados de Calidad de Conacyt la distinción de Doctorado de Competencia Internacional, mientras que la maestría fue aceptada como posgrado en desarrollo. La Dra. Valverde completaba así un círculo de cuando fue una de las primeras discípulas en doctorarse en Estudios Mesoamericanos. Los alumnos de este posgrado la recordarán siempre con un cariño especial, porque tanto como maestra y como coordinadora, escuchó, no sólo a maestros, sino también a los estudiantes, con interés, paciencia y amabilidad, apoyando sin distinción a quien se le acercaba y proyectando esa luz que la caracterizaba.

Con todas estas peculiaridades era un hecho que se le invitara a formar parte de diversas comisiones dictaminadoras, ya que analizaba los expedientes y sus opiniones eran objetivas, apoyando a quien lo merecía, pero sin atacar a quien no llenara los requisitos. Desde 1994 la llamaron de la Escuela Nacional de Antropología e Historia para concursos de oposición; en cuanto a la unam, fue miembro de la Comisión Dictaminadora del Centro Peninsular en Humanidades y Ciencias Sociales, en Yucatán, del Instituto de Investigaciones Históricas, de Estéticas, de Filosóficas, de la Comisión Evaluadora del PRIDE, jurado del Premio Marcos y Celia Maus, del Premio Alejandrina, este último en Querétaro, por mencionar unos cuantos. En todos se distinguió por su buen juicio y su compromiso académico ante cada caso.

La Dra. Valverde tenía mucho todavía por dar a la academia, al conocimiento de los mayas, a esta casa de estudios, a sus compañeros, amigos, alumnos y, por supuesto, a su familia; se fue antes de tiempo, en plena madurez intelectual. Pero tal vez, sin ser egoístas, habría que pensar que ella ya trascendió, que era una persona tan maravillosa que ya no tenía nada que aprender en este plano.

En lo personal, le estoy muy agradecida y me siento afortunada por la amistad que me brindó, por haber tenido la oportunidad de conocerla, por apoyarme siempre en diferentes aspectos de mi vida, por su sonrisa, su actitud positiva, por tener una palabra de aliento en momentos difíciles, por su espíritu de lucha que siempre la acompañó. Esa amistad y esa fortuna de conocerla, que tuvimos muchos, siempre nos acompañará, nos transmitirá esa fuerza por vivir, esa confianza y entusiasmo que mostraba ante cada reto que se le presentaba. Carmen fue una mujer admirable, a la que pondría de ejemplo para 
cualquier circunstancia. Desde luego no es posible referirse a ella sin aludir a su familia, hermanos, cuñados, pero en especial a Arcadio, a Ana Paula y a Julia, que hasta el último momento mostraron un amor y un apoyo inconmensurables, que no es fácil de comprender si no hubiera sido esa esposa y esa madre. Querida Carmen, te recordamos todos con un gran amor y, reitero, agradecimiento. Tu huella, tu luz, permanecerán.

Martha Ilia Nájera C.

Centro de Estudios Mayas,

Instituto de Investigaciones Filológicas, UNAM 